\title{
Body fat and stroke: unmasking the hazards of overweight and obesity
}

\author{
Roger Shinton, Gian Sagar, Gareth Beevers
}

\begin{abstract}
Study objective - It has been frequently noted that overweight and obesity have a stronger relationship to hypertension and diabetes mellitus than to the risk of stroke. The reason for this observation has not been clear. This study aimed to examine the lifelong relation between body fat and stroke to shed light on why the public health risks of overweight and obesity have tended to be obscured in previous epidemiological studies.

Design - Case-control study.

Setting - Eleven general practices in west Birmingham.
\end{abstract}

Participants - Altogether 125 men and women who had just had their first stroke and were aged 35-74 years and 198 controls frequency matched for age and sex were recruited over 24 months during 1988-90. Main results - Those in both the thinnest and fattest quartiles of subscapular skinfold thickness were at increased risk of stroke compared with those in the middle quartiles (age adjusted odds ratios $2 \cdot 12$ (95\% confidence interval (CI) $1 \cdot 2,3 \cdot 9)$ and $2 \cdot 08(1 \cdot 1,3 \cdot 8)$ respectively). When lifelong maximum reported body mass index was assessed the hazards of obesity but not leanness were seen (odds ratio for the highest versus the lowest quartile were - age adjusted, $1.54(0.8,3.0)$ and multiple risk factor adjusted, $2 \cdot 25(1 \cdot 1,4 \cdot 5)$. This lifelong pattern of risk seemed to be established early, the odds ratios for the highest versus the lowest quartile of reported body mass index aged 21 years were - age adjusted, $2 \cdot 18(1 \cdot 1,4 \cdot 4)$ and multiple risk factor adjusted $2 \cdot 13(1 \cdot 1,4 \cdot 2)$. The risks of both maximum reported body mass index and reported body mass index aged 21 years were more clear in those who had never smoked cigarettes (test for trend in odds ratio, $p=0.009$ and $p=0.02$ respectively).

Conclusions - Potentially important risks of excessive body fat for stroke can be obscured by both a history of cigarette smoking and thinness associated with deteriorating health. The results seem to explain why excess body fat has previously been consistently related to hypertension and diabetes mellitus but less consistently to stroke. Avoiding overweight and obesity during adult life offers protection against stroke.

( $f$ Epidemiol Community Health 1995;49:259-264)
The relationship between body fat and stroke has remained surprisingly unclear. Expert committees have not yet agreed that overweight is an established risk factor for stroke, although it is accepted to be causally related to hypertension and diabetes mellitus, both of which are risk factors for stroke. ${ }^{12}$ Many cohort studies seem to indicate little or no adverse risk for stroke with increasing levels of body mass index. ${ }^{3-10}$ It is unclear, however, why overweight is less clearly linked to stroke than it is to hypertension.

Assessment of body fat in epidemiological studies has, conventionally, used relative weight or body mass index. There is now increasing interest in the role of central or truncal body fat as a stronger indicator of both cardiovascular and stroke risk than body mass index. ${ }^{11}{ }^{12}$ These initial observations were based on modest numbers of stroke patients and warranted investigation in studies with larger patient numbers.

There is suggestive evidence from a north Carolina cohort yielding 27 strokes, that the lifelong history of body fat is important in the development of stroke. ${ }^{13}$ This observation has not been followed up but suggested the value of a case-control approach inquiring retrospectively into indices of obesity over a lifelong span. To explore further the nature of the relation between body fat and stroke, subscapular skinfold thickness, body mass index, and lifelong patterns of body fat were assessed in a community based case-control study which aimed to examine a range of lifestyle related risk factors for stroke - the west Birmingham stroke project. The case-control approach allows indices of obesity at the time of the stroke to be assessed together with lifelong patterns.

\section{Methods}

The detailed methods of the case-control study have been previously described. ${ }^{14}{ }^{15}$ People registered with 11 general practices in west Birmingham comprised the study population of 101000 .

\section{STROKE PATIENTS}

Stroke patients included were male and female patients between the ages of 35 and 74 years, whose first stroke occurred between 1 October 1988 and 30 September 1990. Patients were assessed for inclusion by one of us (RS) using the standard World Health Organization criteria - rapidly developing clinical signs of focal and at times global (applied to patients in 
deep coma and to those with subarachnoid haemorrhage) loss of cerebral function, with symptoms lasting more than 24 hours or leading to death, with no apparent cause other than that of vascular origin. ${ }^{16}$ To ensure maximum recruitment, a representative in each practice was telephoned weekly and admission records for Dudley Road Hospital were regularly checked for patients with preliminary diagnoses suggestive of stroke. Both hospital and community stroke patients, if fit, were offered a computerised tomogram of the head (without contrast). Cerebral infarction was diagnosed if a head scan or necropsy was performed within 21 days of stroke onset and there was either no evidence of haemorrhage or a pattern of predominant infarction. The following characteristics excluded stroke patients from the study; a prior history of stroke (but not transient ischaemic attack), a history of mitral valvular heart disease combined with atrial fibrillation, a history of primary or metastatic cerebral neoplasm, a history of coagulation disorder or myeloproliferative disease, patients dying before assessment could be made, and those declining participation.

\section{CONTROL SUBJECTS}

Subjects were randomly selected from the general practice population to match broadly by age and sex the incident stroke case distribution (frequency matching). A high response rate was sought through close liason with the general practitioner when the subject was approached. The same exclusions applied as for stroke patients.

\section{ASSESSMENT}

The cases and controls were all anthropometrically assessed and interviewed by a single observer (RS) using a standard structured questionnaire. Stroke patients were seen as soon as possible after the event. When disability prevented an adequate response the closest relative or friend was interviewed. Harpenden skinfold calipers (John Bull British Indicators Limited, England) were used to measure subscapular skinfold thickness by standard methods. ${ }^{17}$ Skinfold measurements were, with few exceptions, recorded with the subject seated. Two records for each subject were made and the mean calculated. All subjects, when possible, were weighed in light clothing using recently calibrated portable scales with an electronic display (Soehnle, West Germany). Standing height was also measured, when possible, by standard methods ${ }^{17}$ using a portable stadiometer (CMS Weighing Equipment Limited, London). Body mass index was calculated as weight in $\mathrm{kg} /$ (height in $\mathrm{m})^{2}$. Lying height was measured in all stroke patients admitted to hospital. For lying height the subject lay on his/her back and an assistant ensured the heels were correctly positioned at the base of the stadiometer. A simple regression equation which related standing and lying height among stroke patients who could stand enabled standing height to be estimated for those unable to stand. Cases and controls were asked; "What is the most you have ever weighed?" and "About how much did you weigh when you were 21 years old?" The responses were converted into $\mathrm{kg}$ and combined with measured/derived standing height to provide maximum reported body mass index and reported body mass index aged 21.

Measured/derived standing height was combined with the maximum recorded weight, if a record was available, in the general practice or hospital notes to provide maximum recorded body mass index. For all measures of body fat subjects were categorised by quartiles derived from control subjects; these were established separately for males and females. Variables which could confound or interact with the relation of body fat and stroke were assessed by questionnaire and have been detailed previously. ${ }^{1415}$ Local ethical committee approval had been obtained for the study.

\section{STATISTICAL ANALYSIS}

A computer software program $(E G R E T)^{18}$ using methods described by Breslow and Day ${ }^{19}$ was used to calculate odds ratios (relative risk), their $95 \%$ confidence intervals and test for trend in the odds ratios. Mantel-Haentzel methods were used to provide an estimate of the odds ratio after adjustment for one or two other variables. Adjustment was performed using the multiple logistic regression model if there was a need to adjust for more than 2 variables. Regression models were fitted using exposure levels of a given risk factor as discrete (factored) variables. Agreement between reported weights was assessed using $95 \%$ limits of agreement. ${ }^{20}$

\section{Results}

One hundred and twenty five eligible stroke patients were identified over two years. Of the excluded patients 30 had had a prior event, 8 had died before assessment was possible, 3 had haematological disorders, and 1 had mitral valve disease with atrial fibrillation. No stroke patient (or relative) declined to participate. Cerebral infarction was diagnosed in 81 patients, intracerebral haemorrhage in five, and subarachnoid haemorrhage in four. In the remaining 35 patients, computed tomography within 21 days was either impossible or declined by the patient, relative, or attending physician. Assessment was within 7 days for $85(68 \%)$ and within 14 days for $112(90 \%)$

Table 1 Relation between subscapular skinfold thickness and stroke

\begin{tabular}{lll}
\hline $\begin{array}{l}\text { Subscapular skinfold } \\
\text { thickness }\end{array}$ & $\begin{array}{l}\text { Age adjusted odds ratio } \\
(95 \% \text { CI })\end{array}$ & $\begin{array}{l}\text { No of cases: } \\
\text { no of controls }\end{array}$ \\
\hline Males: & & \\
1st quartile & $1 \cdot 0$ & $24: 25$ \\
2nd quartile & $0.67(0 \cdot 25,1 \cdot 76)$ & $16: 25$ \\
3rd quartile & $0.38(0 \cdot 12,1 \cdot 09)$ & $9: 23$ \\
4th quartile & $0.99(0 \cdot 37,2 \cdot 28)$ & $24: 25$ \\
Females: & & \\
1 st quartile & 1.0 & $19: 25$ \\
2nd quartile & $0.44(0 \cdot 11,1 \cdot 36)$ & $6: 25$ \\
3rd quartile & $0.43(0 \cdot 13,1 \cdot 38)$ & $10: 25$ \\
4th quartile & $1.08(0.39,3 \cdot 00)$ & $17: 25$ \\
\hline
\end{tabular}




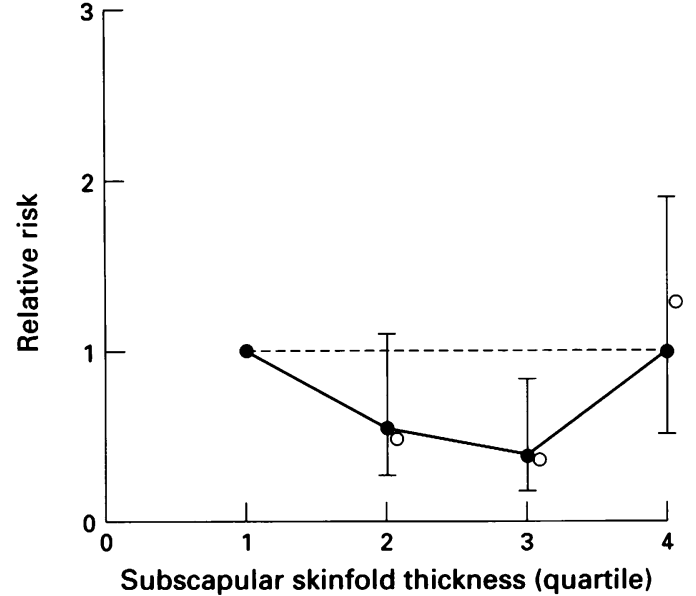

Figure 1 Relation between subscapular skinfold and stroke. $=$ Age adjusted, $\bigcirc=$ multiple risk factor adjusted (age group, race (black/non-black), smoking status (never, former, and current), dietary saturated fat (4 levels), and exercise aged 15 to 25 (yes/no) were included in the model). Bars indicate $95 \%$ confidence intervals.

of cases. Altogether 198 (96\%) of the 207 eligible control subjects agreed to participate. It was originally estimated that recruitment would yield about 150 cases and 150 controls.

Table 2 Relation between body mass index during life and stroke

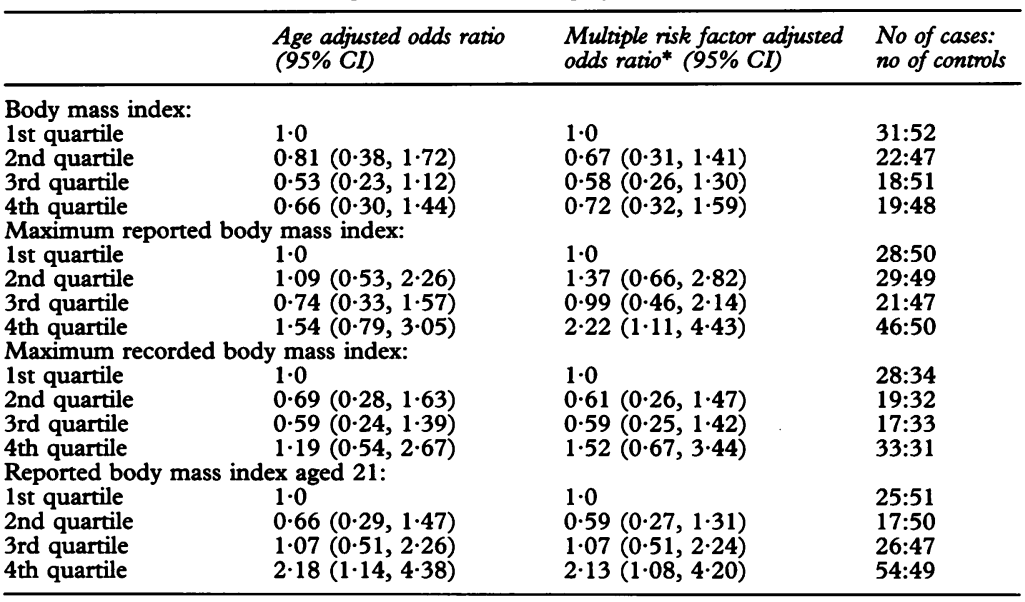

* Multiple risk factor adjusted included age group, race (black/non-black), smoking status (never, former, and current), dietary saturated fat (4 levels), and exercise aged 15 to 25 (yes/no) in the logistic regression model.

Table 3 Relation between body mass index during life and cerebral infarction

\begin{tabular}{|c|c|c|c|}
\hline & $\begin{array}{l}\text { Age adjusted odds ratio } \\
(95 \% \mathrm{CI})\end{array}$ & $\begin{array}{l}\text { Multiple risk factor adjusted } \\
\text { odds ratio* }(95 \% \text { CI) }\end{array}$ & $\begin{array}{l}\text { No of cases: } \\
\text { no of controls }\end{array}$ \\
\hline \multicolumn{4}{|c|}{ Body mass index: } \\
\hline 1st quartile & $1 \cdot 0$ & $1 \cdot 0$ & $20: 52$ \\
\hline 2nd quartile & $0.85(0.36,2.02)$ & $0.70(0.30,1.64)$ & $15: 47$ \\
\hline 3rd quartile & $0.68(0.28,1.61)$ & $0.81(0.34,1.95)$ & $15: 51$ \\
\hline 4th quartile & $0.59(0.23,1.51)$ & $0.65(0.25,1.64)$ & $11: 48$ \\
\hline \multicolumn{4}{|c|}{ Maximum reported body mass index: } \\
\hline 1st quartile & 1.0 & $1 \cdot 0$ & $21: 50$ \\
\hline 2nd quartile & $0.85(0.36,1.95)$ & $1.08(0.47,2.48)$ & $17: 49$ \\
\hline 3rd quartile & $0.60(0.25,1.46)$ & $0.85(0.36,2.03)$ & $14: 47$ \\
\hline 4th quartile & $1.19(0.55,2 \cdot 56)$ & $1.75(0.81,3.79)$ & 28:50 \\
\hline \multicolumn{4}{|c|}{ Maximum recorded body mass index: } \\
\hline 1st quartile & $1 \cdot 0$ & $1 \cdot 0$ & $18: 34$ \\
\hline 2nd quartile & $0.63(0.22,1.70)$ & $0.55(0.20,1.51)$ & $11: 32$ \\
\hline 3rd quartile & $0.53(0.18,1.47)$ & $0.61(0.22,1.65)$ & $11: 33$ \\
\hline 4th quartile & $1.20(0.49,2.98)$ & $1.67(0.68,4.11)$ & 23:31 \\
\hline \multicolumn{4}{|c|}{ Reported body mass index aged 21: } \\
\hline 1st quartile & 1.0 & 1.0 & 21:51 \\
\hline 2nd quartile & $0.50(0.20,1.25)$ & $0.40(0.16,0.99)$ & $11: 50$ \\
\hline 3rd quartile & $0.89(0.39,2.02)$ & $0.88(0.39,1.99)$ & $18: 47$ \\
\hline 4th quartile & $1.43(0.68,3.07)$ & $1.37(0.64,2.90)$ & $30: 49$ \\
\hline
\end{tabular}

* Multiple risk factor adjusted age group, race (black/non-black), smoking status (never, former and current), dietary saturated fat (4 levels) and exercise aged 15 to 25 (yes/no) in the logistic regression model.
The median ages of the patients with stroke and the controls were 66 and 63 respectively. Surrogate responses were required for 30 of the 125 cases and 2 of the 198 controls.

\section{SUBSCAPULAR SKINFOLD THICKNESS}

The following values defined quartiles for subscapular skinfold thickness - males; $13 \cdot 7,17 \cdot 9$, and $23.3 \mathrm{~mm}$, females; 15.2, 22.5 and $30.1 \mathrm{~mm}$. The age adjusted relation between subscapular skinfold and stroke was " $U$ " shaped in both males and females (table 1). As similar patterns were seen in both sexes the results were pooled (fig 1). Individual adjustment of the crude odds ratio by the following had a negligible effect; race, social class, cigarette smoking, alcohol consumption, exercise aged 15 to 25 , recent exercise, dietary fat, history of cardiac ischaemia, and family history of stroke. Adjustments for diabetes and hypertension history reduced the relative risk seen among subjects in the upper quartile: the odds ratio for upper versus lower quartiles were, unadjusted -0.95 , adjusted for history of hypertension $-0 \cdot 80$, and adjusted for history of diabetes mellitus $-0 \cdot 77$. Multiple risk factor adjustment of the relation in both sexes combined made the " $U$ " shape more, rather than less, pronounced (fig 1). The inclusion of hypertension history and history of diabetes in the adjustment was not considered appropriate as it is now widely accepted that these two risk factors are in substantial measure a consequence of overweight. Adjustment would, therefore, only be appropriate in exploring the extent to which hypertension and diabetes were part of a causal pathway involving overweight and stroke. As a prestated objective of the study was to examine a possible increased risk in thin as well as overweight people, an analysis was conducted comparing the upper and lower quartiles with the middle two. The odds ratios, adjusted for age, for the lowest quartile was: $2.12(95 \%$ CI $1.2,3.9)$ and for the upper quartile: $2 \cdot 08$ (95\% CI $1 \cdot 1,3 \cdot 8)$.

\section{BODY MASS INDEX AND STROKE}

Standing height and weight could be measured in all control subjects and 90 of the less disabled stroke patients. Quartiles of body mass index $\left(\mathrm{kg} / \mathrm{m}^{2}\right)$ were defined by the following values: males - 23.7, 25.9 and 28.4 and females $23 \cdot 5,26 \cdot 6$, and $30 \cdot 1$. The risk of stroke did not seem to rise with increasing body mass index (table 2). The pattern was not appreciably altered by multiple risk factor adjustment (covariables as for the subscapular skinfold analysis). A tendency for heavier patients to be more disabled and thus excluded from this analysis cannot be ignored but any effect was likely to be modest.

MAXIMUM REPORTED BODY MASS INDEX

The excess risk seen among those in the thinnest quartile of subscapular skinfold is quite possibly a result of the fact that stroke is not uncommonly a late event in those who are 
Table 4 Relation between body fat and stroke stratified by smoking status

\begin{tabular}{|c|c|c|c|c|c|}
\hline & \multicolumn{4}{|c|}{ Age adjusted odds ratio* (No of cases: number of controls) } & \multirow[t]{3}{*}{ Test for trend } \\
\hline & \multicolumn{4}{|l|}{ Quartile } & \\
\hline & 1 & 2 & 3 & 4 & \\
\hline \multicolumn{6}{|l|}{$\begin{array}{l}\text { Subscapular skinfold thickness: } \\
\text { Never smoker }\end{array}$} \\
\hline Never smoker & $\begin{array}{l}(1 \cdot 0) \\
(6 / 13)\end{array}$ & $\begin{array}{c}0.05 \\
(2 / 22)\end{array}$ & $\begin{array}{c}0.54 \\
(4 / 14)\end{array}$ & $\begin{array}{c}1 \cdot 10 \\
(10 / 20)\end{array}$ & $\mathrm{p}=0.38$ \\
\hline Former smoker & $\begin{array}{l}(1 \cdot 0) \\
(16 / 13)\end{array}$ & $\begin{array}{c}0.57 \\
(9 / 11)\end{array}$ & $\begin{array}{c}0 \cdot 19 \\
(8 / 28)\end{array}$ & $\begin{array}{c}1 \cdot 04 \\
(21 / 17)\end{array}$ & $\mathrm{p}=0.71$ \\
\hline Current smoker & $\begin{array}{l}(1 \cdot 0) \\
(21 / 24)\end{array}$ & $\begin{array}{c}0 \cdot 84 \\
(11 / 17)\end{array}$ & $\begin{array}{l}1 \cdot 12 \\
(7 / 6)\end{array}$ & $\begin{array}{c}1 \cdot 09 \\
(10 / 13)\end{array}$ & $\mathrm{p}=0.72$ \\
\hline \multirow{2}{*}{$\begin{array}{l}\text { Maximum reported body mass index: } \\
\text { Never smoker }\end{array}$} & $(1 \cdot 0)$ & $5 \cdot 13$ & $3 \cdot 58$ & $12 \cdot 80$ & $p=0.009$ \\
\hline & $(1 / 20)$ & $(4 / 14)$ & $(3 / 11)$ & $(13 / 22)$ & \\
\hline Former smoker & $\begin{array}{l}(1 \cdot 0) \\
(9 / 12)\end{array}$ & $\begin{array}{c}0 \cdot 88 \\
(12 / 19)\end{array}$ & $\begin{array}{c}0.59 \\
(11 / 22)\end{array}$ & $\begin{array}{c}1 \cdot 74 \\
(22 / 16)\end{array}$ & $p=0.25$ \\
\hline Current smoker & $\begin{array}{l}(1 \cdot 0) \\
(18 / 18)\end{array}$ & $\begin{array}{r}0.95 \\
(13 / 16)\end{array}$ & $\begin{array}{c}0.55 \\
(7 / 14)\end{array}$ & $\begin{array}{c}0.93 \\
(11 / 12)\end{array}$ & $p=0.67$ \\
\hline $\begin{array}{l}\text { Reported body mass index aged } 21 \text { : } \\
\text { Never smoker }\end{array}$ & $\begin{array}{l}(1 \cdot 0) \\
(3 / 19)\end{array}$ & $\begin{array}{c}1 \cdot 06 \\
(2 / 12)\end{array}$ & $\begin{array}{c}1 \cdot 06 \\
(3 / 18)\end{array}$ & $\begin{array}{c}4 \cdot 33 \\
(13 / 19)\end{array}$ & $p=0.02$ \\
\hline Former smoker & $\begin{array}{l}(1 \cdot 0) \\
(8 / 13)\end{array}$ & $\begin{array}{c}0 \cdot 81 \\
(10 / 20)\end{array}$ & $\begin{array}{c}1.03 \\
(14 / 22)\end{array}$ & $\begin{array}{c}2 \cdot 44 \\
(21 / 14)\end{array}$ & $\mathrm{p}=0.58$ \\
\hline Current smoker & $\begin{array}{l}(1 \cdot 0) \\
(14 / 19)\end{array}$ & $\begin{array}{c}0 \cdot 38 \\
(5 / 18)\end{array}$ & $\begin{array}{l}1 \cdot 74) \\
(9 / 7)\end{array}$ & $\begin{array}{c}1 \cdot 70 \\
(20 / 16)\end{array}$ & $\mathrm{p}=0 \cdot 10$ \\
\hline
\end{tabular}

*Age groupings ( 35 to 54,55 to 64 and 65 to 74 years)

unwell from a variety of medical conditions. To explore this possibility the relation of stroke with maximum reported body mass index was assessed in subjects who could recall maximum weights (cases $=124$, controls $=196$ ). Quartiles were defined by the following values $\left(\mathrm{kg} / \mathrm{m}^{2}\right)$ : male $-25 \cdot 2,27 \cdot 9$, and 30.5 and female $-24 \cdot 8$, $28 \cdot 4$, and $31 \cdot 3$. The apparent excess risk of stroke in thin people disappeared when the relation between lifelong maximum body mass index and stroke was examined (table 2). The hazards of obesity, however, were not obscured. Most stroke patients (26/43) $(60 \%)$ in the thinnest quartile of subscapular skinfold thickness had previously been overweight (maximum reported body mass index quartiles 2 to 4 ). The corresponding figure in controls was $17 / 50$ $(34 \%)$. As a guide to the reliability of recalled maximum weights, responses from stroke patients were compared with those of their relative/friend in a subsample of 20 cases. The surrogate responses had a mean weight only

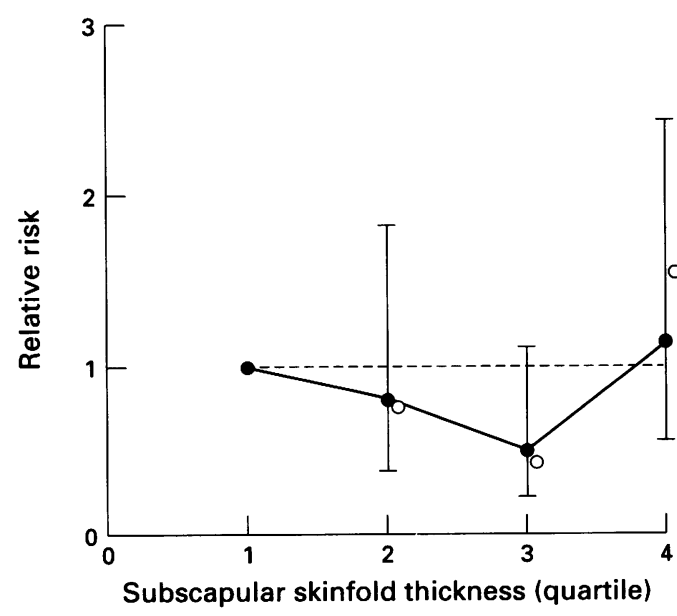

Figure 2 Relation between subscapular skinfold and cerebral infartion. $=$ Age adjusted, $\bigcirc=$ multiple risk factor adjusted (age group, race (black/non black), smoking status (never, former, and current), dietary saturated fat (4 levels) and exercise aged 15 to 25 (yes) no) were included in the model). Bars indicate $95 \%$ confidence intervals.
$0.41 \mathrm{~kg}$ higher than that of the cases themselves. The $95 \%$ limits of agreement were $9 \cdot 1 \mathrm{~kg}$ to $-9.9 \mathrm{~kg}$ (correlation coefficient $=0.95$ ). 18 of the 20 paired responses differed by $6.35 \mathrm{~kg}$ (14lb) or less.

\section{MAXIMUM RECORDED BODY MASS INDEX}

Because a substantial number of cases $(n=97)$ and controls $(n=130)$ had had prior weights recorded, the relation between past maximum recorded body mass index and stroke could be examined. The interquartile values were lower than for the estimated values (male $-24 \cdot 2$, $27 \cdot 9$, and 29.9 and female $-24.0,27 \cdot 5$, and 31.0 ) but the overall relation with the risk of stroke still indicated an increased risk in the most overweight quartile of body mass index (table 2). The " $U$ " shape had reappeared in this analysis, probably because weights tended to be recorded in sicker subjects.

\section{REPORTED 13ODY MASS INDEX AGED 21}

Three stroke patients and one control could not recall their weight when aged 21 . The interquartile values $\left(\mathrm{kg} / \mathrm{m}^{2}\right)$ in control subjects were: male $-21.4,22 \cdot 5$, and $24 \cdot 2$ and female $-20 \cdot 1,21 \cdot 8$, and $23 \cdot 8$. The most overweight subjects were at significantly increased risk of stroke (table 2). The unadjusted odds ratio for the upper quartile of body mass index aged 21 $(2 \cdot 25)$ was reduced somewhat by adjustment for exercise age 15 to $25(1.98)$ but not by maximum reported body mass index (2.39). The pattern in both males and females was similar for all the measures of body mass index (results not presented).

INTER-RELATION OF BODY FAT WITH CIGARETTE SMOKING

Because a clearer relation between overweight and stroke had been noted previously the odds ratios were examined after stratification by cigarette smoking status. ${ }^{20}$ In controls, $24 / 50$ $(48 \%)$ of those in the thinnest quartile of sub- 
scapular skinfold were current smokers compared with $36 / 148(24 \%)$ of controls in higher quartiles. Clear patterns of risk in those who had never smoked were, again, evident in this study (table 3 ). With these stratified analyses the small numbers within individual strata meant that confidence intervals were wide.

\section{CEREBRAL INFARCTION}

The relation between subscapular skinfold thickness and the indices of body mass index was similar to that seen for all stroke patients if the analysis was restricted to the 81 patients with proven cerebral infarction (table 3 , figure 2).

\section{Discussion}

The relation between stroke and the various indices of body fat during life seen in this study helps clarify the importance to stroke prevention of avoiding overweight and obesity. The results help to explain the longstanding dilemma as to why measurement of overweight and obesity at a single point in time is more clearly related to hypertension and diabetes mellitus than it is to the risk of stroke.

The overall results suggest a $U$ shaped relation exists between subscapular skinfold thickness and the risk of stroke. These results support the original hypothesis that people at either end of the body fat distribution are at increased risk. The pattern was similar when cerebral infarction was considered separately. A similar $U$ shaped relation between body fat and stroke has been noted in some cohort studies ${ }^{21-23}$ but most did not stratify body fat by more than two levels. The U shaped relation was seen to have a similar pattern in both males and females. The results support previous findings that the risks of excessive body fat are more clearly seen by measuring truncal fat than by measuring body mass index. ${ }^{1213} \mathrm{~A}$ possible explanation for the advantages of measuring truncal fat over body mass iisdex is that those in generally poor health and at risk of stroke will tend to have a decreasing lean body mass. Skinfold measurements would minimise the impact of this effect.

Other epidemiological studies assessing the hazards of overweight over several decades have also concluded that excessive body fat seems to be causally linked to an increased risk of stroke. Among American college alumni, the more overweight students had a $50 \%$ increased risk of stroke in later years compared with their thinner colleagues. ${ }^{2425}$ Those reporting a history of "clinically diagnosed overweight" in a Dutch hospital based case-control study were at increased risk of stroke (odds ratio $1 \cdot 8$ ). ${ }^{26}$ In two cohort studies with modest numbers of stroke cases there was evidence that reported weight in earlier life is a useful predictor of stroke risk. ${ }^{1323}$ Reports from the Framingham cohort soon after it was established concluded that overweight was of doubtful importance for cardiovascular disease and stroke but the risks were more clearly apparent, particularly for women, at 26 year follow up. ${ }^{27}$ The recently observed link between variability of body weight and coronary heart disease also noted in the Framingham study could be partly explained by the results of our study - those who become obese and then lose weight are at particularly high risk of cardiovascular disease. $^{28}$

Cigarette smoking tended to obscure the true risks of overweight in this study. These observations are consistent with data from the Whitehall and Framingham cohorts for both stroke and cardiovascular disease respectively. ${ }^{2129}$ This interaction of effects is plausible as some smokers, particularly women, report that they smoke to avoid overweight. It must be emphasised, however, that although smoking may help in the short term with overweight it will increase the risk stroke.

The above findings may together explain why a considerable number of studies have concluded that overweight (derived from weight/height) is of minimal importance as a risk factor for stroke. ${ }^{3-10}$ These studies have either had relatively short follow up, body fat stratified by only two levels, or a preponderance of cigarette smokers.

It seems unlikely that the relation between excessive body fat and stroke is due to either study biases or the influence of confounding variables. Separate methods of assessment (subscapular skinfold thickness and maximum reported weight yielding maximum body mass index) both indicated an increased risk. Significant measurement bias by the investigator would seem unlikely because of the high level of repeatability of skinfold measurements. Recall bias is a potential problem in a study such as this, particularly with the inclusion of surrogate responses. Previously recorded weights, however, and the lack of appreciable bias noted when patients and surrogate responses were compared did not indicate particular problems in this study. Loss of height with age is unlikely to have produced an important bias - the impact on body mass index is small and any error introduced is likely to be non-differential. The effect of possible weight loss following stroke could only be small and would only have the effect of underestimating the importance of excessive body fat in this study. The potential problem of residual confounding in adjusted analyses seems unlikely to be important as there was no tendency for adjustment to attenuate the relations that were found (apart from the predicted effects of hypertension or diabetes).

The inter-relationships of diet, exercise, body fat, blood pressure, diabetes mellitus, and other related variables is complex and controversial. This study aimed to explore risks which were related to lifestyle and were potentially under personal control. It was, therefore, a prestated decision not to present the results after adjustment for hypertension and diabetes mellitus. The relative risks of the upper quartiles of all measures of body fat were attenuated by adjusting for a history of diabetes or hypertension. This is likely to reflect the fact that dietary excess and inadequate exercise lead to overweight and its consequent increase in both blood pressure and risk of diabetes. It is being 
realised increasingly that adjustment by variables in the causal pathway is inappropriate except to explore that pathway. ${ }^{30}$ If a hereditary tendency did tend to cause obesity along with hypertension and diabetes the overweight/ stroke relation would have been expected to be reduced by adjustment for a family history of stroke. This was not observed.

\section{CONCLUSION}

This study provides support for the hypothesis that excessive body fat is linked to an increased risk of stroke. This is probably through mechanisms such as hypertension and diabetes mellitus. Intercurrent illness, cigarette smoking and inadequate length of follow up have all tended to obscure these risks in may previous studies. If the prevalence of cigarette smoking falls, the avoidance of excess body fat via dietary prudence and adequate exercise, could emerge more clearly as a lifestyle related risk factor with substantial preventive potential for stroke.

We thank the patients and staff of the 11 participating general practices (see below) for their cooperation, Dr R F Fletcher and Dr R Skinner for their advice and Mrs Beryl Bryant for clerical help. The project was funded by the Wellcome Trust. The participating practices were Bearwood Road Surgery; The participating practices were Bearwood Road Surgery; Smethwick, Birchfield Medical Centre, Cape Hill Medical Centre, Church Lane Surgery; Handsworth, Hamstead Road
Surgery; Handsworth/Great Barr, Lee Bank Health Centre, Surgery; Handsworth/Great Barr, Lee Bank Health Centre, Newtown Health Centre, Plough and Harrow Medical Centre; Ladywood, Sherwood House Surgery; Bearwood,
Health Centre, Victoria Health Centre; Smethwick.

1 Dyken ML, Wolf PA, Barnett HJM, et al. Risk factors in stroke: a statement for physicians by the subcommittee on risk factors and stroke of the Stroke Council. Stroke 1984;15:1105-11.

2 Royal College of Physicians Working Party. Stroke - towards better management. London: Royal College of Physicians, 1989:27.

3 Tanaka H, Veda Y, Hayashi M, et al. Risk factors for cerebral haemorrhage and cerebral infarction in a Japanese rural haemorrhage and cerebral infarction

4 Khaw KT, Barrett-Connor E, Suarez L, Criqui H. Predictors of stroke associated mortality in the elderly. Stroke 1984 of stroke asso.

5 Tanaka H, Hayashi M, Date C, et al. Epidemiologic studies of stroke in Shibata, a Japanese provincial city: preliminar report on risk factors for cerebral infarction. Stroke 1985 16:773-80.

6 Barrett-Connor E, Khaw KT. Diabetes Mellitus: an independent risk factor for stroke? Am $\mathcal{F}$ Epidemiol 1988 128:116-23.

7 Boysen G, Nyboe J, Appleyard M, et al. Stroke incidence and risk factors in Copenhagen, Denmark. Stroke 1988; 19:1345-53.

8 Semenciw RM, Morrison HI, Mao Y, Johansen H, Davies
JW, Wigle DT. Major risk factors for cardiovascular disease mortality in adults: results from the Nutrition Canada Survey Cohort. Int $¥$ Epidemiol 1988;17:317-24.

9 Harmsen P, Rosengren A, Tsipogianni A, Wilhelmsen L Risk factors for stroke in middle-aged men in Goteborg, Risk factors for stroke in middl
Sweden. Stroke 1990;21:223-9.

10 Shaper AG, Phillips AN, Pocock SJ, Walker M, Macfarlane PW. Risk factors for stroke in middle-aged British men. BMF 1991;302:1111-5.

11 Lapidus L, Bengtsson C, Larsson B, Pennert K, Rybo E, Sjostrom L. Distribution of adipose tissue and risk of cardiovascular disease and death: a 12 year follow up of participants in the population study of women in Gothenberg, Sweden. BMF 1984;289:1257-61.

12 Welin L, Svardsudd K, Wilhelmsen L, Larsson B, Tibblin G. Analysis of risk factors for stroke in a cohort of men born in 1913. $N$ Engl f Med 1987;317:521-6.

13 Heyden S, Hames CG, Bartel A, Cassel JC, Tyroler HA, Cornoni JC. Weight and weight history in relation to cerebrovascular and ischaemic heart disease. Arch Interm Med 1971;128:956-60.

14 Shinton R, Sagar G, Beevers G. The relation of alcohol consumption to cardiovascular risk factors and stroke. The west Birmingham stroke project. $f$ Neurol Neurosurg Psychiatry 1993;56:458-62.

15 Shinton R, Sagar G. Lifelong exercise and stroke. $B M \mathcal{F}$ $1993 ; 307: 231-4$

16 World Health Organisation. Cerebrovascular diseases - prevention, treatment and rehabilitation. Technical report series no 469. WHO: Geneva, 1971.

17 Weiner JS, Lourie JA. Human biology: a guide to field methods. IBP Handbook No 9. Oxford: Blackwell Scientific Publications, 1969:27-52.

18 EGRET. Reference manual. Seattle: Statistics and epidemiology research corporation, 1990

19 Breslow NE, Day NE. Statistical methods in cancer research. volume I - The analysis of case-control studies. Lyon: International agency for research on cancer, 1980: 122-159.

20 Bland JM, Altman DG. Statistical methods for assessing agreement between two methods of clinical measurement. Lancet 1988; i: $307-10$.

21 Shinton R, Shipley M, Rose G. Overweight and stroke in the Whitehall study. $₹$ Epidemiol Comm Health 1991;45: the Whiteh

22 Okada H, Horibe H, Ohno Y, Hayakawa N, Aoki N. A prospective study of cerebrovascular disease in Japanese rural communities, Akabane and Asahi. Stroke 1976;6: 599-607.

23 Rhoads GG, Kagan A. The relation of coronary heart disease, stroke and mortality to weight in youth and middle age. Lancet 1983;i:492-5.

24 Paffenbarger RS, Wing AL. Characteristics in youth predisposing to fatal stroke in later years. Lancet 1967;i: 753-4.

25 Paffenbarger RS, Wing AL. Chronic disease in former college students: early precursors of non-fatal stroke. $A m \mathcal{F}$ Epidemiol 1971;94:524-30.

26 Herman B, Schmitz PIM, Leyten ACM, et al. Multivariate logistic analysis of risk factors for stroke in Tilburg, The logistic analysis of risk factors for stroke in Tilbur

27 Hubert HB, Feinleib M, McNamara PM, Castelli WP. Obesity as an independent risk factor for cardiovascular disease: a 26-year follow up of participants in the Framingham heart study. Circulation 1983;67:96877

28 Lissner L, Odell PM, D'Agostino RB, et al. Variability of body weight and health outcomes in the Framingham population. N Engl F Med 1991;324:1839-44.

29 Harris T, Cook FE, Garrison R, Higgins M, Kannel W, Goldman L. Body mass index and mortality among nonsmoking older persons. $¥ A M A$ 1988;259:1520-24.

30 Rothman KJ. Modern epidemiology. Little Brown and Company, Boston 1986:89-94. 